\title{
Does participation in a weight control program also improve clinical and functional outcomes for Chinese patients with schizophrenia treated with olanzapine?
}

This article was published in the following Dove Press journal:

Neuropsychiatric Disease and Treatment

10 July 2014

Number of times this article has been viewed

\author{
William Montgomery' \\ Tamas Treuer ${ }^{2}$ \\ Wenyu $\mathrm{Ye}^{3}$ \\ Hai Bo Xue ${ }^{4}$ \\ Sheng $\mathrm{Hu} \mathrm{Wu} \mathrm{W}^{4}$ \\ Li Liu ${ }^{4}$ \\ Zbigniew Kadziola ${ }^{5}$ \\ Michael D Stensland ${ }^{6}$ \\ Haya Ascher-Svanum ${ }^{7}$ \\ 'Global Health Outcomes Eli Lilly \\ Australia Pty Ltd, West Ryde, NSW, \\ Australia; ${ }^{2}$ Neuroscience Research, \\ Eli Lilly and Company, Budapest, \\ Hungary; ${ }^{3}$ Global Statistical Sciences, \\ Lilly Suzhou Pharmaceutical Company, \\ Ltd, Shanghai, People's Republic of \\ China; ${ }^{4}$ Medical Department, Lilly \\ Suzhou Pharmaceutical Company, Ltd, \\ Shanghai, People's Republic of China; \\ ${ }^{5}$ Global Statistical Sciences, Eli Lilly \\ GmbH, Vienna, Republic of Austria; \\ ${ }^{6}$ Agile Outcomes Research, Inc., \\ Rochester, MN, USA; ${ }^{7}$ Global Health \\ Outcomes, Eli Lilly and Company, \\ Indianapolis, IN, USA
}

Correspondence: William Montgomery Eli Lilly Australia, I 12 Wharf Road, West Ryde, NSW, Australia

Tel +6I 293254335

Fax +6I 293254334

Email montgomery_bill@lilly.com
Objectives: This study examined whether participation in a weight control program (WCP) by patients with schizophrenia treated with olanzapine was also associated with improvements in clinical and functional outcomes.

Methods: A post-hoc analysis was conducted using data from the Chinese subgroup ( $n=330)$ of a multi-country, 6-month, prospective, observational study of outpatients with schizophrenia who initiated or switched to oral olanzapine. At study entry and monthly visits, participants were assessed with the Clinical Global Impression of Severity, and measures of patient insight, social activities, and work impairment. The primary comparison was between the 153 patients who participated in a WCP at study entry $(n=93)$ or during the study $(n=60)$ and the 177 patients who did not participate in a weight control program (non-WCP). Mixed Models for Repeated Measures with baseline covariates were used to compare outcomes over time. Kaplan-Meier survival analysis was used to assess time to response.

Results: Participants had mean age of 29.0 years and 29.3 years, and $51.0 \%$ and $57.6 \%$ were female for WCP and non-WCP groups, respectively. Average initiated daily dose for olanzapine was $9.5 \pm 5.4 \mathrm{mg}$. WCP participants gained less weight than non-participants (3.9 kg vs $4.9 \mathrm{~kg}$, $P=0.03)$ and showed statistically significant better clinical and functional outcomes: greater improvement in illness severity $(-2.8$ vs $-2.1, P<0.001)$, higher treatment response rates $(94.1 \%$ vs $80.9 \%, P<0.001)$, shorter time to response $(P<0.001)$, and greater improvement in patients' insight $(P<0.001)$. Patients who enrolled in a WCP during the study had greater initial weight gain than those who enrolled at baseline $(P<0.05)$, but similar total weight gain.

Conclusion: Participation in a WCP may not only lower the risk of clinically significant weight gain in olanzapine-treated patients, but may also be associated with additional clinical and functional benefits.

Keywords: body weight, olanzapine, schizophrenia, epidemiologic studies, prospective studies

\section{Introduction}

Schizophrenia is a chronic and disabling mental illness ${ }^{1,2}$ that affects approximately $0.78 \%$ of the population in the People's Republic of China. ${ }^{3}$ The core symptoms of schizophrenia include positive symptoms, such as delusions, hallucinations, disorganized speech, and bizarre behavior; and negative symptoms, such as flat emotions, reduced speech, and reduced goal-driven behavior. ${ }^{1}$ The Chinese diagnostic system also requires a loss of insight to be present during the acute phase of the illness. ${ }^{4}$ Lack of insight in schizophrenia has been linked to poor treatment adherence, ${ }^{5,6}$ which is a robust predictor of relapse. 
The World Health Organization ranks schizophrenia among the top ten causes of years lost due to disability. ${ }^{8}$ Due to the social impairment, marriage rates among individuals with schizophrenia are lower than those in the general population. In the People's Republic of China, the percentage of married individuals in samples of individuals with schizophrenia has ranged from $10.9 \%$ to $46.7 \% .{ }^{9-13}$ Similarly, work impairment is also very common in patients with schizophrenia. Despite the low rates of unemployment found in the People's Republic of China, the unemployment rate for patients with schizophrenia has been reported to be considerably higher at $37.1 \%$ to $61.5 \% .^{10-13}$

Since their introduction in the 1950 s, antipsychotic medications have been the cornerstone for the management of patients with schizophrenia. ${ }^{2,14}$ The antipsychotics can be grouped into first-generation antipsychotics (FGA) and second-generation antipsychotics (SGA) based primarily on their time of release relative to clozapine. ${ }^{15}$ Meta-analytic research has found that the SGAs have a reduced risk for extrapyramidal symptoms (EPS) and some of the SGAs are more efficacious than the FGAs. ${ }^{16}$ Due in part to these advantages, the SGAs have largely replaced the FGAs in usual clinical care. ${ }^{17,18}$

The SGAs are not a homogeneous group of medications. Reviews and meta-analyses have found that clozapine and olanzapine appear to be the most effective antipsychotics for controlling symptoms, ${ }^{19,20}$ but these two medications have also been associated with greater increases in body weight and other metabolic parameters. ${ }^{19,21,22}$ Concerns about the risk of neutropenia with clozapine as well as metabolic issues with olanzapine and clozapine have likely limited the use of these agents, despite the need for more effective treatments for most patients with schizophrenia.

A growing body of research has found that pharmacological and behavioral interventions may help reduce antipsychotic-associated weight gain in patients with serious mental illnesses. A meta-analysis pooling randomized controlled trials (RCTs) of different pharmacological interventions (amantadine, d-fenfluarmine, dextroamphetamine, famotidine, fluoxetine, metformin, nizatidine, reboxetine, sibutramine, and topirmiate) found that they were modestly effective for preventing and treating weight gain in patients with schizophrenia. ${ }^{23}$ However, the different agents appear to have heterogeneous effects, and more long-term studies with larger sample sizes are needed. ${ }^{23,24}$ The same metaanalysis also examined behavioral interventions, which were effective for both preventing some weight gain and reducing body weight among antipsychotic-treated patients who had gained weight. ${ }^{23}$ A more recent meta-analysis examining RCTs of behavioral weight control interventions among antipsychotic-treated patients with schizophrenia or other serious mental illnesses found that the interventions reduced body mass index (BMI) by $0.98 \mathrm{~kg} / \mathrm{m}^{2}$ relative to no intervention. ${ }^{25}$ A third meta-analysis examining prospective studies, including non-randomized studies, of cognitive behavioral interventions for weight gain among antipsychotic-treated patients reported a $4.24 \mathrm{~kg}$ lower body weight for studies with a 6-month duration. ${ }^{26}$ Meta-analyses of pharmacological and behavioral interventions to reduce antipsychotic-associated weight gain have demonstrated that these interventions are effective in reducing the amount of weight gain for patients with schizophrenia and other serious mental illnesses.

Surprisingly, none of the randomized studies of behavioral interventions from the meta-analyses reported clinical outcomes. Two observational studies reported statistically significant improvements in symptom ratings from the beginning of the study, ${ }^{27,28}$ but the improvements were not significantly different from the control groups. Another very small observational study of eleven olanzapine-treated patients with schizophrenia failed to find significant changes on clinical measures. ${ }^{29}$ A recent single-arm study of 33 Taiwanese outpatients with schizophrenia found that, not only did patients lose weight when they participated in a behavioral weight control program (WCP), they also demonstrated improvements in the symptoms of schizophrenia, health-related quality of life, anxiety and depressive symptoms, and sleep. ${ }^{30}$

A few observational studies have reported that patients with either bipolar disorder or schizophrenia who were treated with antipsychotics and participated in behavioral WCPs demonstrated clinical improvement as well as reduced weight gain. ${ }^{27-30}$ This analysis used data from the Chinese sites of an observational study that was designed to examine factors associated with weight gain among patients initiated on or switched to olanzapine therapy. The objective of the current study was to investigate whether patients with schizophrenia who participated in WCPs had greater improvements in clinical or functional outcomes than patients who did not participate in WCPs.

\section{Methods}

\section{Study design}

The study was a post-hoc analysis using data from the subgroup ( $n=330)$ of Chinese patients with schizophrenia from eleven investigative sites (hospitals and mental health centers) in urban areas of mainland China, of a multi-country 
(including patients from Mexico, Romania, People's Republic of China, and Taiwan), 6-month, prospective, single-arm, observational study of outpatients who were initiated or switched to oral olanzapine treatment. ${ }^{31,32}$ Patients were enrolled into the study between July 2005 and December 2006. This analysis contrasted the outcomes for patients who participated in WCPs and patients who did not participate in a WCP at any time during the study (non-WCP). In addition, the analysis compared outcomes between the WCP patients who were enrolled in the WCPs at baseline (baseline WCP) and the WCP patients who enrolled in WCPs after baseline (postbaseline WCP). The same baseline was used in this analysis as in the parent study, ie, the baseline visit was the visit at which patients were initiated or switched to oral olanzapine. ${ }^{31,32}$

In this observational study, the treating physicians and patients made all of the treatment decisions, including enrollment in WCPs. Each patient's treating physician was responsible for prescribing an appropriate dose and oral formulation of olanzapine (standard tablet or orally disintegrating tablets). Adjunct psychotropic therapy and other concomitant medications, prescribed as part of standard clinical care, were permitted throughout the study. Patients who discontinued olanzapine remained in the study and were followed until the 6-month visit, unless they were lost to follow-up or withdrew from the study.

The study was approved by the institutional ethics review board at each site, and each patient consented to the release of their data before any study assessments were performed. Patients or their legal guardians signed the informed consent forms. The study sponsor did not provide medications and the patients were not paid for their participation in the study.

\section{Inclusion/exclusion criteria}

Eligible patients initiated or switched to oral olanzapine. In the parent study, patients were required to have a diagnosis of schizophrenia or bipolar disorder according to the criteria in the Diagnostic and Statistical Manual for Mental Disorders, Fourth Edition - Text Revision (DSM-IV-TR) or International Classification of Diseases, Tenth Revision (ICD-10). In the Chinese subpopulation used in the current analysis, all patients were diagnosed with schizophrenia. All patients were at least 18 years old and receiving treatment in an outpatient, ambulatory, or community setting. Patients participating in any separate interventional study were excluded.

\section{Assessments}

Patients were assessed at baseline and at monthly ( \pm 2 weeks) intervals for up to 6 months. In addition to demographics, height, illness duration, smoking status, and medical comorbidities that were assessed at baseline, multiple outcome variables were examined at each of the monthly visits.

Outcome variables included body weight, measures of illness severity, work impairment, social activities, patient insight, and pharmacological treatment. Illness severity was measured by the Clinical Global Impression - Severity (CGI-S), a 7-point scale assessing the patient's current severity of mental illness (1: normal, not at all ill, 2: borderline mentally ill, 3: mildly ill, 4: moderately ill, 5: markedly ill, 6: severely ill, or 7: extremely ill). Response was defined as a 2-point decrease (improvement) in the CGI-S rating from baseline to follow-up when baseline assessment was between 5 and 7 points, or a 1-point decrease when baseline was between 2 and 4 points. ${ }^{33}$ Work impairment in the past month was measured using a simple 5-point investigator-rated question (0: no impairment, 1: mild impairment, 2: moderate impairment, 3: severe impairment, 4: unable to work due to mental illness). The number of social activities in the last 4 weeks was measured using a simple 6-point investigator-rated question $(0,1,2,3,4,5+)$. Patient insight into their illness at the time of assessment was measured using a simple 5-point investigator-rated question (0: none, 1: low, 2: medium, 3: moderate, or 4: high). Finally, previous and current antipsychotic and concomitant medications were assessed at each study visit.

\section{Details of the WCPs}

Participation in the WCPs was voluntary and based on physician recommendations or patient decision. The WCPs were provided by each site (state-managed hospitals or mental health care centers in urban areas of mainland China). The WCPs varied in their structure across the different sites; however, common elements included psychoeducation and the provision of information and tips on healthy living nutrition, fitness, and exercise. The programs were delivered in an individual or group setting on a regular basis. Information was collected at baseline on the following elements of the WCP in which a patient participated: individual or group sessions, nutritional consultation, behavioral intervention, discussion of the potential consequences of weight gain before initiation of antipsychotic therapy, and lifestyle consultation.

\section{Statistical methods}

Univariate comparisons were conducted using Fisher's exact tests for categorical variables and analysis of variance (ANOVA) for continuous variables. Mixed models for repeated measures (MMRM) adjusted for the baseline 
measure, baseline body weight, baseline CGI-S, and duration of illness were used to model change from baseline in: CGI-S, weight, work impairment, number of social activities, and patient insight. Kaplan-Meier survival analysis was used to assess time to first response to olanzapine. The primary comparison in the models was between non-WCP and WCP with a secondary comparison between the baseline WCP and post-baseline WCP groups. All analyses were completed using SAS software (v9.2; SAS Institute, Cary, NC, USA) with a two-tailed alpha of 0.05 .

\section{Results}

\section{Study population}

The sample consisted of 330 patients with schizophrenia from the study sites in the People's Republic of China. A total of 153 patients participated in a WCP, including 93 patients who either enrolled in, or who were already participating, in a WCP at baseline (baseline WCP) and 60 patients who initiated a WCP at any time during the course of the study (post-baseline WCP). The remaining 177 patients who did not participate in a WCP made up the non-WCP group. Table 1 gives the baseline characteristics for each cohort.

Nearly all of the study participants completed the full 6-month study, 150 (98.0\%) of the WCP participants and 175 (98.9\%) of the non-WCP participants $(P=0.80)$. During the study, nine $(5.9 \%)$ of the WCP participants and $14(7.9 \%)$ of the non-WCP participants discontinued olanzapine treatment $(P=0.52)$. Over the course of the study 70 (75\%) patients who were in the baseline WCP group continued to participate in the WCPs through to the end of the study. The average initiated daily dose for olanzapine was $9.5 \pm 5.4 \mathrm{mg}$ and the average daily olanzapine dose during the study was $12.1 \pm 5.1 \mathrm{mg} /$ day. Antipsychotic polypharmacy was used at some point during the study to treat six (3.9\%) of the WCP participants and 28 $(15.8 \%)$ of the non-WCP participants $(P<0.001)$.

\section{Body weight change}

In the MMRM model that adjusted for baseline body weight, CGI-S, work impairment, and duration of illness, the WCP patients gained less weight $(3.9 \mathrm{~kg})$ than the non-WCP patients ( $4.9 \mathrm{~kg}, P=0.03$ ). Baseline WCP and post-baseline WCP patients had a different pattern of change in body weight (Figure 1). At the first two monthly visits, the postbaseline WCP patients had greater weight gain than the baseline WCP patients, but at the end of the study, differences in weight change between the baseline WCP $(3.7 \mathrm{~kg})$ and post-baseline WCP (4.2 kg) groups were not significant $(P=0.42)$. Clinically significant weight gain $(\geq 7 \%)$ was observed in $42.1 \%$ of the WCP and $49.7 \%$ of the non-WCP participants $(P=0.18)$. Clinically significant weight change between the baseline WCP $(37.0 \%)$ and post-baseline WCP $(50.0 \%)$ groups was not significantly different $(P=0.13)$.

Table I Baseline characteristics

\begin{tabular}{|c|c|c|c|c|c|c|}
\hline Characteristic & $\begin{array}{l}\text { Non-WCP } \\
(n=177)\end{array}$ & $\begin{array}{l}\text { All WCP } \\
(n=\mid 53)\end{array}$ & $\begin{array}{l}\text { Baseline WCP } \\
(n=93)\end{array}$ & $\begin{array}{l}\text { Post-baseline WCP } \\
(n=60)\end{array}$ & $P$-value ${ }^{a}$ & $P$-value ${ }^{b}$ \\
\hline Age $(y)$, mean $\pm S D$ & $29.3 \pm 10.4$ & $29.0 \pm 10.5$ & $29.2 \pm 9.9$ & $28.6 \pm 11.3$ & 0.812 & 0.717 \\
\hline Female (\%) & 57.6 & 51.0 & 50.5 & 51.7 & 0.268 & 1.000 \\
\hline Married (\%) & 24.9 & 29.4 & 31.2 & 26.7 & 0.731 & 0.732 \\
\hline Working for pay (\%) & 14.7 & II.I & 12.9 & 8.3 & 0.070 & 0.068 \\
\hline Independent living (\%) & 6.8 & 12.4 & I5.| & 8.3 & $<0.001$ & 0.239 \\
\hline Duration of illness (years), mean \pm SD & $4.6 \pm 8.6$ & $2.8 \pm 5.8$ & $2.9 \pm 6.2$ & $2.6 \pm 4.9$ & 0.029 & $0.84 I$ \\
\hline Initial olanzapine dose $(\mathrm{mg})$, mean $\pm \mathrm{SD}$ & $9.6 \pm 5.6$ & $9.4 \pm 5.2$ & $9.2 \pm 4.7$ & $9.5 \pm 5.8$ & 0.757 & 0.744 \\
\hline CGI-S, mean $\pm \mathrm{SD}$ & $4.6 \pm 1.2$ & $4.8 \pm 1.1$ & $4.8 \pm 1.0$ & $4.9 \pm 1.1$ & 0.082 & 0.574 \\
\hline Prior antipsychotic therapy (\%) & 70.5 & 49.0 & 45.2 & 55.6 & $<0.001$ & 0.236 \\
\hline BMI $\left(\mathrm{kg} / \mathrm{m}^{2}\right)$, mean $\pm \mathrm{SD}$ & $22.0 \pm 2.9$ & $21.9 \pm 2.9$ & $21.9 \pm 2.5$ & $21.8 \pm 3.6$ & 0.733 & 0.844 \\
\hline Prior weight gain during antipsychotic therapy (\%) & 4.5 & 13.7 & 12.9 & 15.0 & 0.006 & 0.811 \\
\hline Normal weight (BMI category) (\%) & 75.7 & 80.4 & 81.7 & 78.3 & $0.54 I$ & 0.083 \\
\hline Non-smokers (\%) & 81.8 & 74.1 & 76.7 & 69.8 & 0.253 & 0.831 \\
\hline Weight $(\mathrm{kg})$, mean $\pm \mathrm{SD}$ & $61.3 \pm 10.5$ & $60.5 \pm 10.1$ & $60.5 \pm 8.6$ & $60.5 \pm 12.2$ & $0.47 I$ & 0.980 \\
\hline Number of social activities, mean $\pm \mathrm{SD}$ & $1.8 \pm 1.9$ & $1.6 \pm 1.7$ & $1.5 \pm 1.5$ & $1.8 \pm 1.9$ & 0.326 & 0.461 \\
\hline Patient insight, mean \pm SD & $1.4 \pm 1.2$ & $1.3 \pm 1.2$ & $1.2 \pm 1.1$ & $1.5 \pm 1.5$ & 0.503 & 0.107 \\
\hline Work impairment, mean \pm SD & $2.5 \pm 1.1$ & $2.3 \pm 1.3$ & $2.3 \pm 1.3$ & $2.3 \pm 1.3$ & 0.195 & 0.987 \\
\hline
\end{tabular}

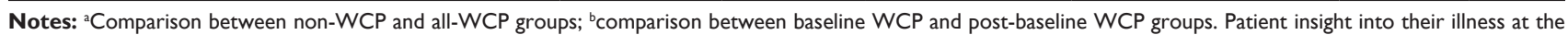
time of assessment was measured using a simple 5-point investigator-rated question (0: none, I: low, 2: medium, 3: moderate, or 4: high). Work impairment in the past month was measured using a simple 5-point investigator-rated question (0: no impairment, I: mild impairment, 2: moderate impairment, 3: severe impairment, 4: unable to work due to mental illness).

Abbreviations: BMI, body mass index; CGI-S, Clinical Global Impression of Severity; SD, standard deviation; WCP, weight control program. 


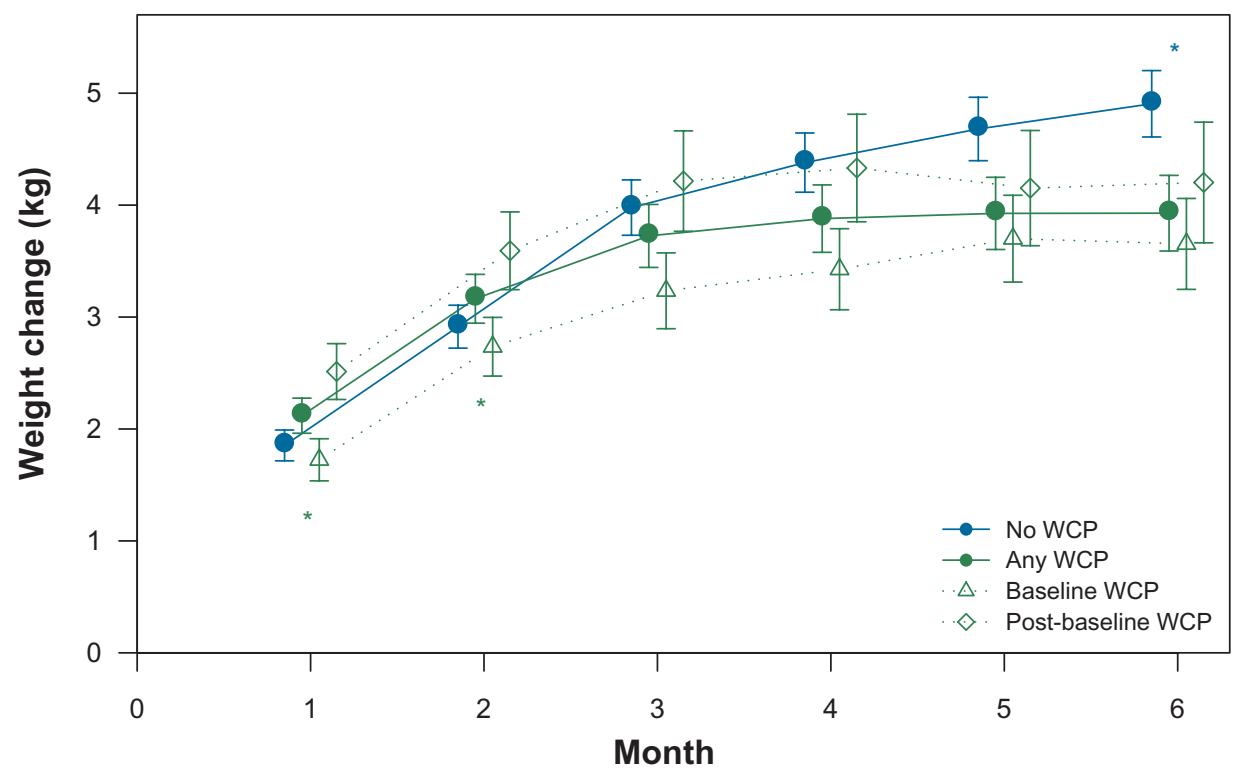

Figure I Body weight change.

Notes: The values in the figure represent the LS means from the MMRM. The blue asterisks indicate the monthly comparison between the non-WCP and any WCP groups, and the green asterisks represent the monthly comparisons between the baseline WCP and post-baseline WCP groups; $* P<0.05$.

Abbreviations: LS, least squares; MMRM, mixed models for repeated measures; WCP, weight control program.

\section{Symptom reductions}

The MMRM analysis showed significantly greater reductions in CGI-S for the WCP group beginning at visit 2 and remaining at each visit through to the end of the 6-month study ( -2.8 vs $-2.1, P<0.001$; Figure 2 ). When examining the percent of responders on the CGI-S, there was a significantly higher percentage in the WCP group (94.1\%) as compared to the non-WCP group $(80.9 \%, P<0.001)$. The percent of responders in the baseline WCP $(95.7 \%)$ and post-baseline WCP groups was similar $(91.5 \%, P=0.31)$. In a time-to-event model, the WCP group showed a significantly shorter time to response relative to the non-WCP group $(P<0.001$; Figure 3$)$, but the baseline WCP and post-baseline WCP groups were not significantly different $(P=0.15)$.

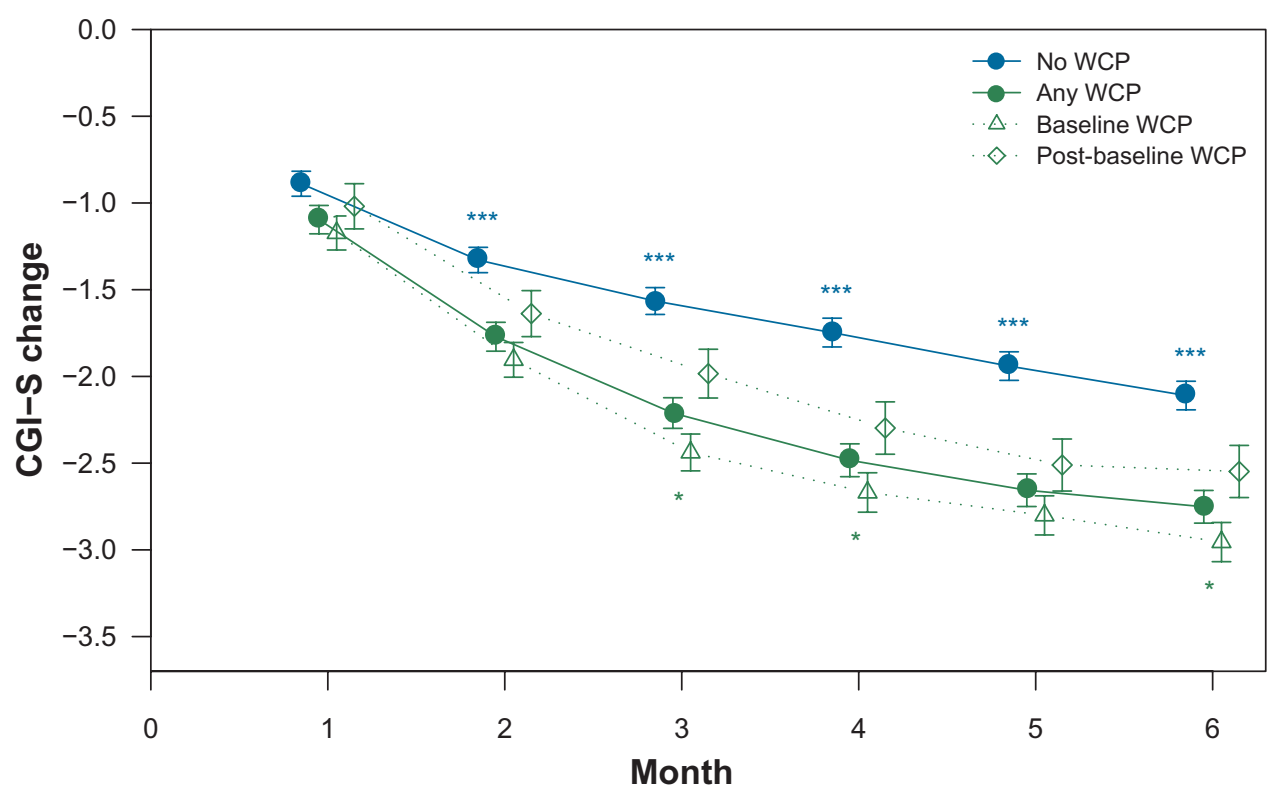

Figure 2 CGI-S change.

Notes: The values in the figure represent the LS means from the MMRM. The asterisks indicate statistical significance level (*P $<0.05$; $* * * P<0.00 \mathrm{I})$. The blue asterisks indicate the monthly comparison between the non-WCP and any WCP groups, and the green asterisks represent the monthly comparisons between to the baseline WCP and post-baseline WCP groups.

Abbreviations: CGI-S; Clinical Global Impression of Severity; LS, least squares; MMRM, mixed models for repeated measures; WCP, weight control program. 


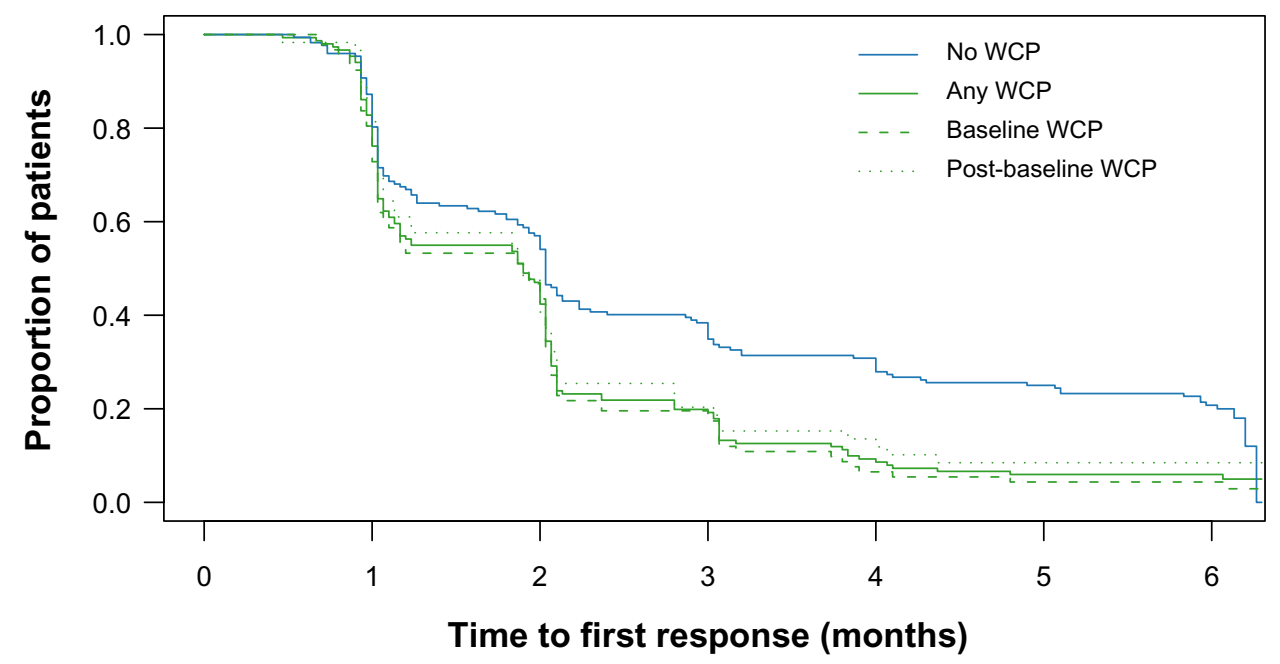

Figure 3 Time to first response during the study.

Notes: The log-rank tests showed that the patients who participated in any WCP had a significantly shorter time to symptomatic response than the non-WCP patients $(P<0.00 \mathrm{I})$. There was no significant difference between baseline WCP and the post-baseline WCP patients $(P=0.15)$.

Abbreviation: WCP, weight control program.

\section{Work impairment, level of insight, and social activities}

The MMRM model controlling for baseline work impairment, CGI-S, body weight, and duration of illness found that work impairment improved significantly more for the WCP than the non-WCP patients at months 4 and 5, but the differences were not significant between the baseline WCP and post-baseline WCP groups at any visit (Figure 4). The MMRM model controlling for baseline body weight, CGI-S, insight, and duration of illness found that patients in WCPs had significantly higher improvements in insight at each visit (2.01 vs $1.43, P<0.001)$ than the non-WCP patients (Figure 5). At the end of the study, the improvements in insight for the baseline WCP group were similar to those for the post-baseline WCP group ( 2.16 vs $1.85, P=0.09$ ). Finally, the MMRM model examining the number of social activities during the study did not find any significant changes over time or between the WCP groups (Figure 6).

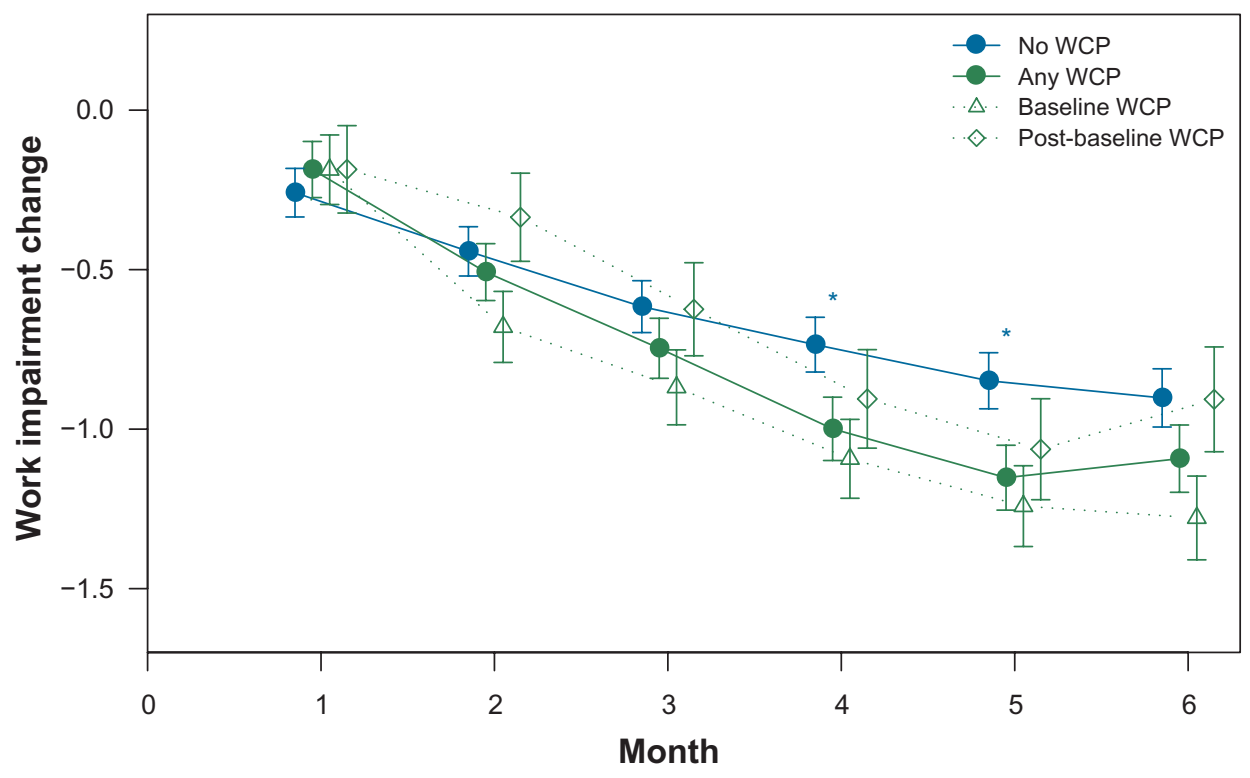

Figure 4 Change in work impairment.

Notes: The values in the figure represent the LS means from the MMRM. The blue asterisks indicate statistical significance level $(* P<0.05)$ of the monthly comparison between the non-WCP and any WCP groups.

Abbreviations: LS, least squares; MMRM, mixed models for repeated measures; WCP, weight control program. 


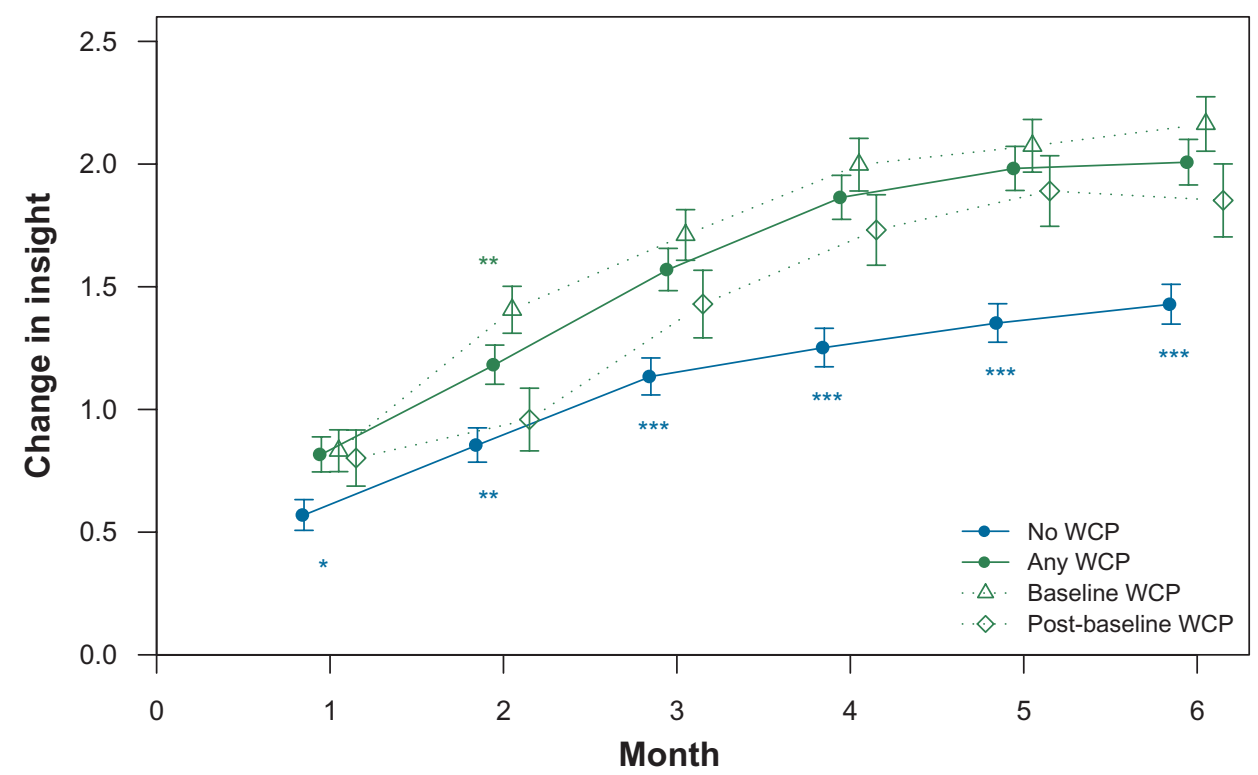

Figure 5 Change in patient insight.

Notes: The values in the figure represent the LS means from the MMRM. The blue asterisks indicate statistical significance level $(* P<0.05$; $* * P<0.01$; $* * * P<0.00$ I) of the monthly comparison between the non-WCP and any WCP groups, and the green asterisks represent the monthly comparisons between to baseline WCP and post-baseline WCP groups.

Abbreviations: LS, least squares; MMRM, mixed models for repeated measures; WCP, weight control program.

\section{Discussion}

Effective antipsychotics can only work if patients take the medications. Unfortunately, many patients with schizophrenia struggle with adherence to oral antipsychotics, in part because they often lack the cognitive insight to be adherent to prescribed medications. ${ }^{5}$ Poor treatment adherence with antipsychotic medication is one of the strongest predictors of relapse $\mathrm{e}^{7,34}$ and may lead to a worsening course of illness. ${ }^{5}$ Treatment adherence can be improved with both behavioral ${ }^{35}$ and pharmacological interventions. In particular, multiple studies have found that patients tend to persist with certain antipsychotic medications for a longer length of time than other antipsychotics. ${ }^{36-38}$ Unfortunately, some studies have shown that the more effective antipsychotics, such as clo-

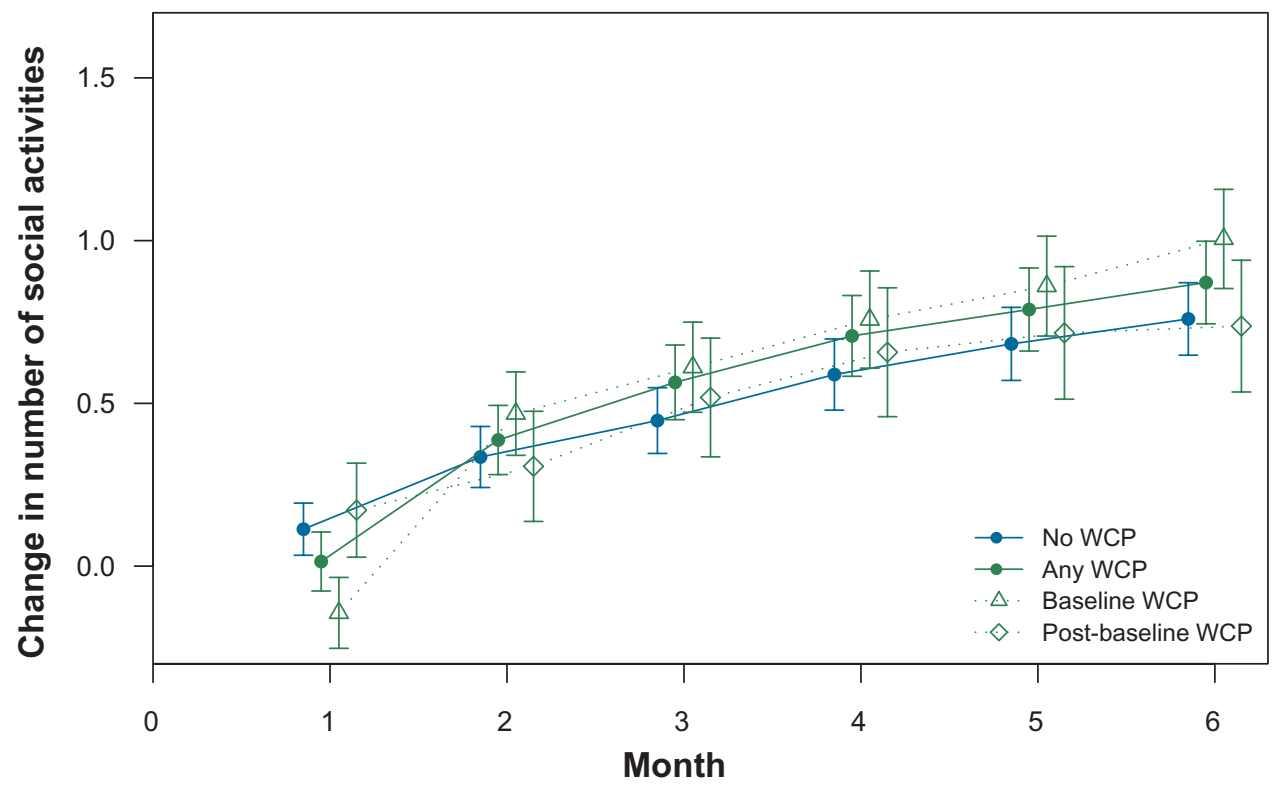

Figure 6 Change in social activities.

Note: The values in the figure represent the LS means from the MMRM.

Abbreviations: LS, least squares; MMRM, mixed models for repeated measures; WCP, weight control program. 
zapine and olanzapine, have also been associated with the greatest weight gain, ${ }^{21,22,39}$ and it has been hypothesized that there may be a link between clinical improvement and weight gain in patients with schizophrenia. ${ }^{39-41}$

In this study, we found that olanzapine-treated patients who participated in WCPs gained significantly less weight than non-participants (3.9 kg vs $4.9 \mathrm{~kg}, P=0.03$ ). In addition, the WCP participants demonstrated statistically significant better outcomes than non-WCP participants across a range of clinical and functional measures, including: greater improvement in illness severity as measured by the CGI-S ( -2.8 versus [vs] $-2.1, P<0.001)$, higher treatment response rates $(94.1 \% \mathrm{vs}$ $80.9 \%, P<0.001)$, shorter time to response $(P<0.001)$, greater improvement in the level of insight $(P<0.001)$, lower rates of antipsychotic polypharmacy ( $3.9 \%$ vs $15.8 \%, P<0.001)$, and reduced work impairment $(P<0.05$ at months 4 and 5$)$. In this analysis, patients with schizophrenia treated with olanzapine who participated in a WCP not only gained less weight but also had improved clinical and functional outcomes.

The finding that WCPs had a modest effect in reducing weight gain for patients with schizophrenia treated with olanzapine is consistent with previous research on antipsychotics and weight gain, including meta-analyses that have examined the impact of both behavioral and pharmacological interventions. ${ }^{23,25,26}$ Weight control interventions that are initiated in conjunction with antipsychotic treatment have been found to reduce weight gain, and those implemented after the patient gained weight, have been shown to reduce body weight. $^{23}$ The observed pattern of weight gain in this study showed the greatest mean change occurring early in treatment, and later weight gain occurred more slowly. This pattern is consistent with analyses of much larger samples. ${ }^{42,43}$

A simple examination of mean weight change over time does not capture the full pattern of individual patients' weight gain. Approximately $25 \%$ of olanzapine patients have been found to lose weight during treatment, 50\% gain between 0-9 kgs, and $25 \%$ gain $>9 \mathrm{~kg} .{ }^{42}$ Thus, the amount of weight change depends on the specific patient. To help identify patients who are at a higher risk of antipsychoticassociated weight gain, the Weight Gain Risk Factor Checklist (WGRF-16) has been developed. ${ }^{44}$ The WGRF-16 identifies 16 different patient and treatment response characteristics that predict weight gain such as lower baseline BMI, ${ }^{45-47}$ younger age, ${ }^{45,47}$ appetite changes, ${ }^{32}$ and early weight gain. ${ }^{48}$

Very little prior research has reported clinical outcomes for antipsychotic-treated patients participating in WCPs. A few observational studies have reported improved clinical outcomes from baseline, ${ }^{27,28,30}$ but improvements relative to a control group have not been previously reported. The precise mechanisms by which WCPs lead to improved outcomes cannot be determined from this study; however, behavioral programs targeting schizophrenia have been shown to lead to better outcomes in schizophrenia when combined with medication. ${ }^{35,49}$ The clinical and functional improvements for the patients in the WCPs may reflect a non-specific effect related to increased social support, resulting in improved insight or better treatment adherence; however, more research is needed.

\section{Limitations}

This was a post-hoc analysis from a larger multi-country, observational, single-arm study; thus, the results should be interpreted with caution. The WCP cohorts were not formed by randomization and differed at baseline, creating the potential for confounding and biased comparisons.

Analyses were adjusted for a select set of baseline covariates; however, the potential for bias due to unmeasured confounders or other baseline differences remains. Although a comprehensive set of factors was assessed in this study, some relevant factors were not assessed (eg, cumulative olanzapine dose and the duration and cumulative doses of prior antipsychotic and mood stabilizer therapy). Weight gain prior to this study was not controlled for in the analysis, and there was considerable variation among participants in the WCPs in terms of the duration and the nature of their participation. The details of the WCPs that patients may have participated in prior to the study (eg, duration, content of the WCP, or how it was delivered) were not assessed. Several of the outcomes measured in this study were assessed using simple clinician-rated scales developed for this study. These scales have not been previously validated. Future research could also examine the contribution to clinical change from the different elements of behavioral WCP (ie, behavioral intervention, education, life counseling, nutrition, exercise). Replication of the current findings with RCTs is needed.

\section{Conclusion}

For patients from the People's Republic of China recently initiated on or switched to olanzapine, participation in a WCP may not only lower the risk of weight gain, but it may also be associated with improvements in a range of clinical and functional outcomes. Patients who experience significant weight gain at the beginning of therapy may be at risk of interrupting their antipsychotic treatment even if it is effective. Referring patients to WCPs may allow them to continue benefiting 
from their antipsychotic treatment efficacy, while further benefiting from the potential non-specific effects of weight control programs on insight as well as clinical and functional rehabilitation. Further investigation of the long-term impact of WCPs on the outcomes of patients taking antipsychotic medications is warranted.

\section{Acknowledgment}

Funding for this study was provided by Eli Lilly and Company, Indianapolis, IN, USA.

\section{Disclosure}

WM, TT, WY, HBX, SHW, LL, ZK, and HAS are employees of Eli Lilly and Company or its subsidiaries. MDS provided medical writing assistance and was funded by Eli Lilly and Company. The authors declare no other conflicts of interest in this work.

\section{References}

1. American Psychiatric Association. Diagnostic and Statistical Manual of Mental Disorders DSM-IV-TR Fourth Edition. 4th ed. Washington, DC: American Psychiatric Publishing, Inc.; 2000.

2. Lehman AF, Lieberman JA, Dixon LB, et al. Practice guideline for the treatment of patients with schizophrenia, second edition. Am J Psychiatry. 2004;161(Suppl 2):1-56.

3. Phillips MR, Zhang J, Shi Q, et al. Prevalence, treatment, and associated disability of mental disorders in four provinces in China during 2001-2005: an epidemiological survey. Lancet. 2009;373(9680): 2041-2053.

4. Phillips MR. Characteristics, experience, and treatment of schizophrenia in China. Dialogues Clin Neurosci. 2001;3(2):109-119.

5. Buckley PF, Wirshing DA, Bhushan P, Pierre JM, Resnick SA, Wirshing WC. Lack of insight in schizophrenia: impact on treatment adherence. CNS Drugs. 2007;21(2):129-141.

6. Le Quach P, Mors O, Christensen T, et al. Predictors of poor adherence to medication among patients with first-episode schizophrenia-spectrum disorder. Early Interv Psychiatry. 2009;3:66-74.

7. Novick D, Haro JM, Suarez D, Perez V, Dittmann RW, Haddad PM. Predictors and clinical consequences of non-adherence with antipsychotic medication in the outpatient treatment of schizophrenia. Psychiatry Res. 2010;176(2-3):109-113.

8. Mathers C, Boerma T, Fat DM. The Global Burden of Disease: 2004 Update. Geneva, Switzerland: World Health Organization; 2008.

9. Phillips MR, Lu SH, Wang RW. Economic reforms and the acute inpatient care of patients with schizophrenia: the Chinese experience. Am J Psychiatry. 1997;154(9):1228-1234.

10. Xiang YT, Wang CY, Wang Y, et al. Socio-demographic and clinical determinants of quality of life in Chinese patients with schizophrenia: a prospective study. Qual Life Res. 2010;19(3):317-322.

11. Xiang YT, Wang CY, Weng YZ, et al. Predictors of relapse in Chinese schizophrenia patients: a prospective, multi-center study. Soc Psychiatry Psychiatr Epidemiol. 2011;46(12):1325-1330.

12. Xiang YT, Weng YZ, Leung CM, Tang WK, Ungvari GS. Quality of life of Chinese schizophrenia outpatients in Hong Kong: relationship to sociodemographic factors and symptomatology. Aust NZJ Psychiatry. 2007;41(5):442-449.

13. Yeung F, Chan S. Clinical characteristics and objective living conditions in relation to quality of life among community-based individuals of schizophrenia in Hong Kong. Qual Life Res. 2006;15(9):1459-1469.
14. Falkai P, Wobrock T, Lieberman J, Glenthoj B, Gattaz WF, Möller H-J. World Federation of Societies of Biological Psychiatry (WFSBP) guidelines for biological treatment of schizophrenia, Part 1: acute treatment of schizophrenia. World J Biol Psychiatry. 2005;6(3):132-191.

15. Leucht S, Kissling W, Davis JM. Second-generation antipsychotics for schizophrenia: can we resolve the conflict? Psychol Med. 2009; 39(10):1591-1602.

16. Leucht S, Corves C, Arbter D, Engel RR, Li C, Davis JM. Secondgeneration versus first-generation antipsychotic drugs for schizophrenia: a meta-analysis. Lancet. 2009;373(9657):31-41.

17. An FR, Xiang YT, Wang CY, et al. Change of psychotropic drug prescription for schizophrenia in a psychiatric institution in Beijing, China between 1999 and 2008. Int J Clin Pharmacol Ther. 2010;48(4): 270-274.

18. Prah P, Petersen I, Nazareth I, Walters K, Osborn D. National changes in oral antipsychotic treatment for people with schizophrenia in primary care between 1998 and 2007 in the United Kingdom. Pharmacoepidemiol Drug Saf. 2012;21(2):161-169.

19. Attard A, Taylor DM. Comparative effectiveness of atypical antipsychotics in schizophrenia: what have real-world trials taught us? CNS drugs. 2012;26(6):491-508.

20. Leucht S, Komossa K, Rummel-Kluge C, et al. A meta-analysis of head-to-head comparisons of second-generation antipsychotics in the treatment of schizophrenia. Am J Psychiatry. 2009;166(2):152-163.

21. Allison DB, Mentore JL, Heo M, et al. Antipsychotic-induced weight gain: a comprehensive research synthesis. Am J Psychiatry. 1999;156(11):1686-1696.

22. Rummel-Kluge C, Komossa K, Schwarz S, et al. Head-to-head comparisons of metabolic side effects of second generation antipsychotics in the treatment of schizophrenia: a systematic review and meta-analysis. Schizophr Res. 2010;123(2-3):225-233.

23. Faulkner G, Cohn T, Remington G. Interventions to reduce weight gain in schizophrenia. Schizophr Bull. 2007;33(3):654-656.

24. Hoffmann VP, Case M, Jacobson JG. Assessment of treatment algorithms including amantadine, metformin, and zonisamide for the prevention of weight gain with olanzapine: a randomized controlled open-label study. J Clin Psychiatry. 2012;73(2):216-223.

25. Bonfioli E, Berti L, Goss C, Muraro F, Burti L. Health promotion lifestyle interventions for weight management in psychosis: a systematic review and meta-analysis of randomised controlled trials. $B M C$ Psychiatry. 2012;12(1):78.

26. Gabriele JM, Dubbert PM, Reeves RR. Efficacy of behavioural interventions in managing atypical antipsychotic weight gain. Obes Rev. 2009;10(4):442-455.

27. Centorrino F, Wurtman JJ, Duca KA, et al. Weight loss in overweight patients maintained on atypical antipsychotic agents. Int J Obes (Lond). 2006;30(6):1011-1016.

28. Poulin MJ, Chaput JP, Simard V, et al. Management of antipsychoticinduced weight gain: prospective naturalistic study of the effectiveness of a supervised exercise programme. Aust N Z J Psychiatry. 2007; 41(12):980-989.

29. Ball MP, Coons VB, Buchanan RW. A program for treating olanzapinerelated weight gain. Psychiatr Serv. 2001;52(7):967-969.

30. Chen CK, Chen YC, Huang YS. Effects of a 10-week weight control program on obese patients with schizophrenia or schizoaffective disorder: a 12-month follow up. Psychiatry Clin Neurosci. 2009;63(1):17-22.

31. Ang Q, Tang J, Zhao J. Factors associated with weight gain during six-month olanzapine therapy. Chin J Psychiatry. 2011;44(3).

32. Treuer T, Hoffmann VP, Chen AK-P, et al. Factors associated with weight gain during olanzapine treatment in patients with schizophrenia or bipolar disorder: results from a six-month prospective, multinational, observational study. World J Biol Psychiatry. 2009;10(4 Pt 3): 729-740.

33. Haro JM, Edgell ET, Novick D, et al. Effectiveness of antipsychotic treatment for schizophrenia: 6-month results of the Pan-European Schizophrenia Outpatient Health Outcomes (SOHO) study. Acta Psychiatr Scand. 2005;111(3):220-231. 
34. Leucht S, Tardy M, Komossa K, Heres S, Kissling W, Davis JM. Maintenance treatment with antipsychotic drugs for schizophrenia. Cochrane Database Syst Rev. 2012;5:CD008016.

35. Guo X, Zhai J, Liu Z, et al. Effect of antipsychotic medication alone vs combined with psychosocial intervention on outcomes of early-stage schizophrenia: a randomized, 1-year study. Arch Gen Psychiatry. 2010;67(9):895-904.

36. Gaebel W, Riesbeck M, von Wilmsdorff M, et al. Drug attitude as predictor for effectiveness in first-episode schizophrenia: results of an open randomized trial (EUFEST). Eur Neuropsychopharmacol. 2010;20(5):310-316.

37. Haro JM, Suarez D, Novick D, Brown J, Usall J, Naber D. Three-year antipsychotic effectiveness in the outpatient care of schizophrenia: observational versus randomized studies results. Eur Neuropsychopharmacol. 2007;17(4):235-244.

38. Lieberman JA, Stroup TS, McEvoy JP, et al. Effectiveness of antipsychotic drugs in patients with chronic schizophrenia. $N$ Engl J Med. 2005;353(12):1209-1223.

39. Ascher-Svanum H, Stensland MD, Kinon BJ, Tollefson GD. Weight gain as a prognostic indicator of therapeutic improvement during acute treatment of schizophrenia with placebo or active antipsychotic. J Psychopharmacol. 2005;19(Suppl 6):110-117.

40. Treuer T, Karagianis J, Hoffmann VP. Can increased food intake improve psychosis? A brief review and hypothesis. Curr Mol Pharmacol. 2008;1(3):270-272.

41. Treuer T, Karagianis J. Is hunger a driver of the cognitive development? Neuropsychopharmacology. 2006;31(10):2326-2327; author reply 2328.
42. Bushe CJ, Slooff CJ, Haddad PM, Karagianis JL. Weight change from 3-year observational data: findings from the worldwide schizophrenia outpatient health outcomes database. J Clin Psychiatry. 2012;73(6): e749-e755.

43. Millen BA, Campbell GM, Beasley CM. Weight changes over time in adults treated with the oral or depot formulations of olanzapine: a pooled analysis of 86 clinical trials. J Psychopharmacol. 2011;25(5): 639-645.

44. Treuer T, Pendlebury J, Lockman H, et al. Weight Gain Risk Factor assessment checklist: overview and recommendation for use. Neuro Endocrinol Lett. 2011;32(2):199-205.

45. Basson BR, Kinon BJ, Taylor CC, Szymanski KA, Gilmore JA, Tollefson GD. Factors influencing acute weight change in patients with schizophrenia treated with olanzapine, haloperidol, or risperidone. J Clin Psychiatry. 2001;62(4):231-238.

46. Choong E, Bondolfi G, Etter M, et al. Psychotropic drug-induced weight gain and other metabolic complications in a Swiss psychiatric population. J Psychiatr Res. 2012;46(4):540-548.

47. Lee SY, Park MH, Patkar AA, Pae CU. A retrospective comparison of BMI changes and the potential risk factors among schizophrenic inpatients treated with aripiprazole, olanzapine, quetiapine or risperidone. Prog Neuropsychopharmacol Biol Psychiatry. 2011;35(2):490-496.

48. Case M, Treuer T, Karagianis J, Hoffmann VP. The potential role of appetite in predicting weight changes during treatment with olanzapine. BMC Psychiatry. 2010;10:72.

49. Grant PM, Huh GA, Perivoliotis D, Stolar NM, BeckAT. Randomized trial to evaluate the efficacy of cognitive therapy for low-functioning patients with schizophrenia. Arch Gen Psychiatry. 2012;69(2):121-127.
Neuropsychiatric Disease and Treatment

\section{Publish your work in this journal}

Neuropsychiatric Disease and Treatment is an international, peerreviewed journal of clinical therapeutics and pharmacology focusing on concise rapid reporting of clinical or pre-clinical studies on a range of neuropsychiatric and neurological disorders. This journal is indexed on PubMed Central, the 'PsycINFO' database and CAS.

\section{Dovepress}

The manuscript management system is completely online and includes a very quick and fair peer-review system, which is all easy to use. Visit http://www.dovepress.com/testimonials.php to read real quotes from published authors. 